\title{
Diagnosis of Avipoxvirus Infection in a Bluejay (Cyanocitta cristata) with Hepatic Necrosis Using Negative Contrast Electron Microscopy and Ultramicrotomy of Infected Cell Cultures
}

\author{
C.E. Hearne, J.L. Cavender, and T.D. O’Toole \\ Department of Veterinary Sciences, University of Wyoming, Laramie, WY 82070
}

Avian poxviruses of the Avipoxvirus genus have a worldwide distribution. A wide variety of domestic and wild birds are infected, resulting in various disease syndromes. In November 2001, the carcass of a free-ranging bluejay (Cyanocitta cristata) was submitted to the Wyoming State Veterinary Laboratory, Laramie, WY for diagnosis. The bird was found staggering with labored breathing and died shortly thereafter. A red-tailed hawk was diagnosed with poxvirus infection in the same property two years earlier. Histopathologic studies of the bluejay's tissues revealed acute multifocal hepatic necrosis and no detectable viral inclusion bodies. Tissue samples were taken for virus isolation and transmission electron microscopy (TEM).

Virus isolation in cell culture was performed according to Hsiung ${ }^{1}$. A 10\% homogenate of liver was prepared and inoculated onto chicken embryonic fibroblast (CEF) cells that were held at $37^{\circ} \mathrm{C}$. The wells were examined daily for cytopathic effect using an Olympus CK2 inverted microscope (Olympus America Inc., Lake Success, NY, USA). A cytopathic effect was evident after 3 days in culture (Figure 1). The cells were scraped from the culture wells and prepared for negative contrast electron microscopy (NCEM) examination ${ }^{2}$ and TEM ultrathin sectioning $^{3,4,5,6}$.

The NCEM prepared grids from the cell cultures were screened for the presence of viral particles using a Philips 410LS transmission electron microscope (FEI Co., Hillsboro, OR, USA). Numerous poxvirus were observed (Figure 2). Ultrathin sections from the epoxy embedded cell cultures revealed characteristic poxvirus virions (arrows) in the cell cytoplasm (Figure 3).

Virus isolation in cell culture increased the population of virus from infected tissues to a number detectable by NCEM and epoxy embedded ultrathin sections. These techniques confirmed the presence of the virus in the tissue and aided in the final diagnosis of the affected bluejay.

References:

[1] G.D. Hsiung, Diagnostic Virology, Yale Univ. Press: New Haven, (1982) 38.

[2] H.K. Whitaker and C. Alderson, Amer. Assn. Vet. Diag. $23^{\text {rd }}$ Ann. Proceed. (1980) 321.

[3] R.L. Moses, Electron Microscopy Society of America Bulletin. 19 (1989) 60.

[4] B. Plantholt, Proceedings Electron Microscopy Society of America. 15 (1985) 106.

[5] S.I. Purdy-Ramos and M. S. Forbes, Jnl. of Electron Microscopy Techniques. 1 (1984) 271.

[6] C.E. Hearne et al., Microscopy and Microanalysis. 7 (2001) 752. 


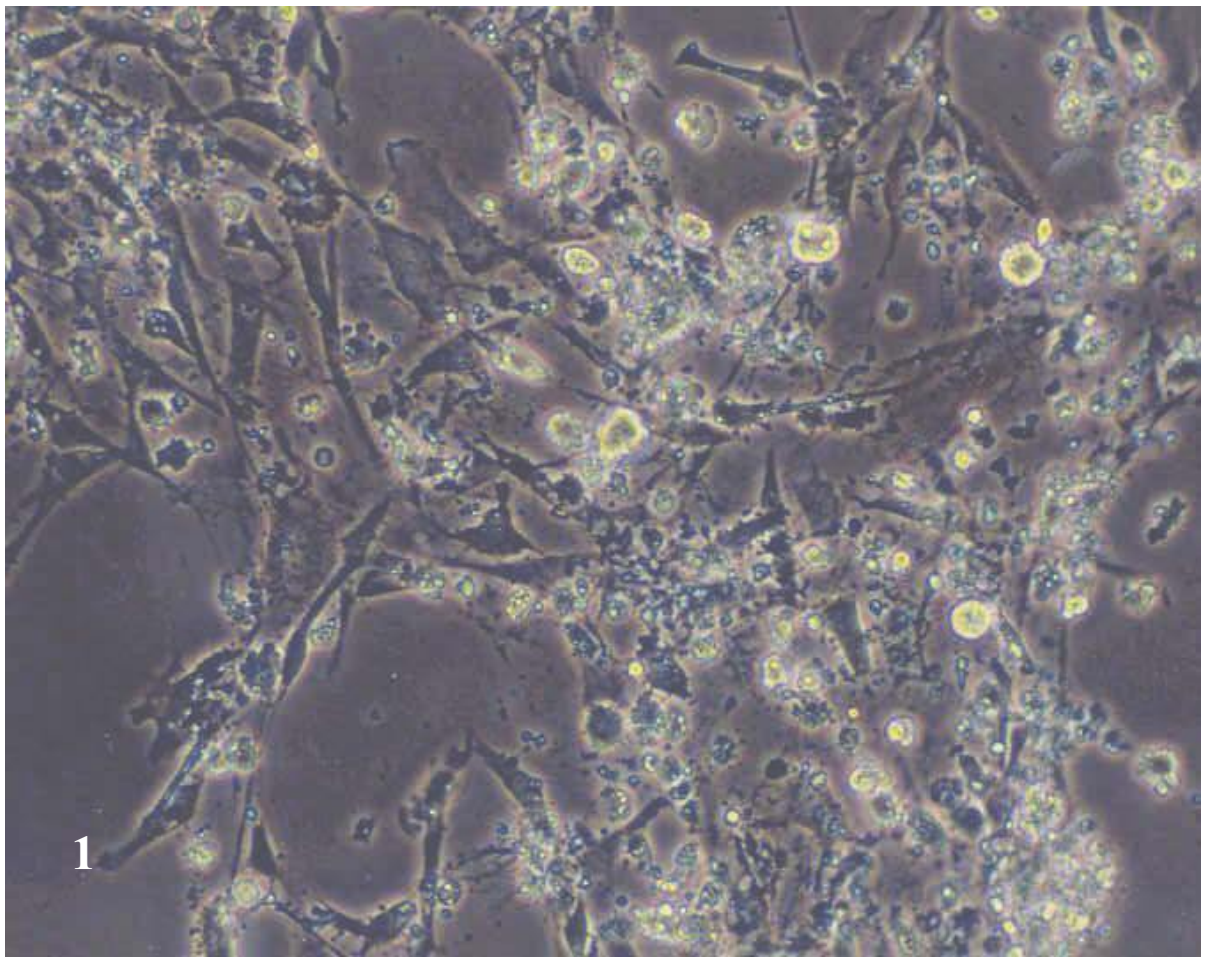

FIG. 1. Poxvirus infected CEF cells from bluejay.
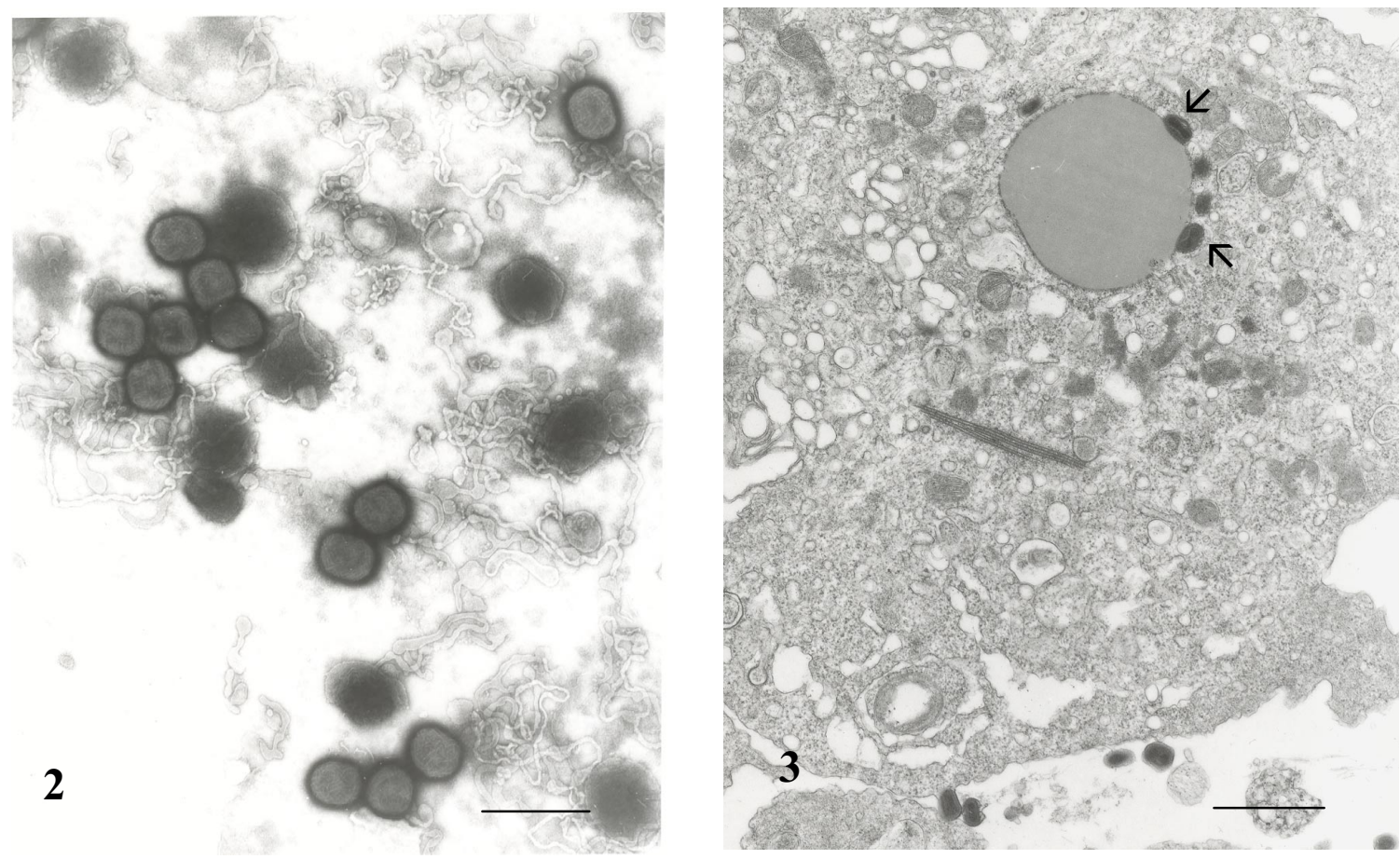

FIG. 2. NCEM of poxvirus in CEF cells from bluejay. Marker $=500 \mathrm{~nm}$

FIG. 3. Ultrathin section of poxvirus infected CEF cells from bluejay. Marker $=0.1 \mu$ 